\title{
CONCEPÇÕES DE UMA PROFESSORA DE CIÊNCIAS SOBRE O USO DE SITUAÇÕES-PROBLEMA
}

\section{CONCEPTS OF A SCIENCE TEACHER ON THE USE OF PROBLEM-SITUATIONS}

\author{
Maria Valgerlene de Souza Lima \\ Universidade Federal Rural de Pernambuco, valgerlene@gmail.com \\ José Euzebio Simões Neto \\ Universidade Federal Rural de Pernambuco, euzebiosimoes@gmail.com \\ Flávia Cristiane Vieira da Silva \\ Universidade Federal Rural de Pernambuco, flavia.cristianevs@gmail.com
}

\section{Resumo}

O objetivo desse artigo foi analisar as concepções de uma professora de ciências do nível fundamental sobre o trabalho com situações-problema, a partir de uma proposta de experiência formativa individual, elaborada considerando a construção, a aplicação e a avaliação de situações-problema no ensino de ciências. Os dados foram coletados a partir das observações feitas durante a formação individual, da aplicação de questionários e da realização de entrevista semiestruturada e posteriormente analisados. Realizamos a pesquisa uma professora de ciências do Ensino Fundamental da rede pública estadual de Pernambuco, em Calumbi, Sertão do Pajeú. As diferentes atividades realizadas permitiram ao docente uma reflexão e melhor compreensão do uso de situaçõesproblema como estratégia didática, além de ter permitido vivenciar e discutir a utilização de situações-problema como estratégia didática para o ensino de ciências.

Palavras-chave: Ensino de Ciências. Concepções. Situações-Problema.

\section{Abstract}

The aims of this article was to analyze the conceptions of a science teacher of basic level about work with problem-situations, based on a proposal of individual formation experience, elaborated considering the construction, application and evaluation of problem-situations in science teaching. The data were collected from the observations made during the individual formation, from the application of questionnaires and from the semi-structured interview and subsequently analyzed. We carried out the research a science teacher of fundamental level of the public network of Pernambuco, in Calumbi, Pajeú countryside. The different activities carried out allowed the teacher to reflect on and better understand the use of problem-situations as a didactic strategy, in addition to allowing them to experience and discuss the use of problem-situations as a didactic strategy for teaching science.

Keywords: Science Teaching. Conceptions. Problem-Situations. 


\section{Introdução}

A química escolar pode ser considerada uma disciplina difícil de aprender. Uma das razões para que muitos estudantes não aprendam os conceitos químicos, nos variados níveis do ensino, pode ser a falta de compreensão dos significados e da validade do que estudam, ou seja, não conseguem associar os fenômenos estudados com os fenômenos que ocorrem no cotidiano. Talvez a falta de abordagem cotidiana ou contextualizada, que terminam por produzir uma ciência escolar asséptica (ZANON e PALHARINI, 1995; CHASSOT, 1993; 1995), ou seja, a ciência livre de sujeiras, apresentada de forma limpa e organizada, na qual o conhecimento científico é apresentado de forma neutra, sem contexto e desvinculada da realidade. Sabemos que nos livros didáticos mais recentes existe uma maior preocupação em apresentar contextos, trazendo, por exemplo temas sociocientíficos (BEZERRA e AMARAL, 2015) e aplicações dos conceitos, essa assepsia ainda é marcante e direciona uma prática docente desvinculada do que compõe o cotidiano dos estudantes. Essa assepsia também está associada a visão da ciência como uma construção realizada exclusivamente por mentes privilegiadas, sendo atribuição única do professor transmitir informações aos seus alunos sobre aquilo que já foi desenvolvido. Acreditamos que tal abordagem é uma das causas das dificuldades de aprendizagem e do pouco interesse dos estudantes em aprender ciências.

Muitas são as estratégias didáticas que podem ser usadas para tentar amenizar tais dificuldades no ensino e aprendizagem de ciências. Nesta pesquisa, destacamos a utilização de situações-problema, baseado nas ideias de Meirieu (1998), que as define da seguinte forma:

Uma situação didática na qual se propõe ao sujeito uma tarefa que ele não pode realizar sem efetuar uma aprendizagem precisa. $E$ essa aprendizagem, que constitui o verdadeiro objetivo da situação-problema, se dá ao vencer obstáculos na realização da tarefa (MERIEU, 1998, p. 192).

Para Cachapuz (1999), a resolução de situações-problema pode ser o ponto de partida para a aprendizagem, pois quando estão diretamente relacionadas a contextos reais e significativos para os estudantes, que despertem a atenção e o interesse e que possam ser inseridas nas temáticas curriculares estudadas nos níveis médio e fundamental, podem ser consideradas como motivadoras para a aprendizagem. Portanto, trata-se de ir ao encontro de objetivos educacionais que busquem o desenvolvimento pessoal e social dos estudantes, em que os conteúdos e processos deixem de ser fins para se transformarem em meios de encontrar respostas possíveis sobre questões, agora portadoras de significados mais amplos.

De acordo com Simões Neto, Marcelino-Jr. e Campos (2013), a situação-problema deve necessariamente ser um problema contextualizado, no qual é introduzido um obstáculo, que deve ser superado para que ocorra aprendizagem. Ainda, dois sistemas são "instalados" quando da proposição de uma situação problema: i) sistema de restrição, que delimita o espaço teórico para resolução, que tem por finalidade evitar que estudante atribua uma resposta banal ao problema, desviando da ação de aprender; ii) sistema de recursos, que são as estratégias, ferramentas e materiais didáticos auxiliares que dirigem 
o processo de aprendizagem e dão subsídios para a superação do obstáculo (MEIRIEU, 1998).

Ressaltamos a importância do contexto escolhido para a elaboração da situaçãoproblema, pois ela deve despertar o interesse do aprendiz, ou seja, deve proporcionar aos estudantes a possibilidade de organização das suas ideias, como estado psicológico. Nesta direção, Silva e Núñez (2002) afirmam que, ao trabalhar com uma estratégia didática baseada na resolução de situações-problema:

...cria-se um estado psíquico de dificuldade intelectual, quando se apresenta uma tarefa que não pode ser explicada e/ou resolvida com os meios de que se dispõe. Este estado psíquico, conhecido como situaçãoproblema, deve caracterizar-se por ser a consequência de uma contradição dialética. (SILVA; NÚÑEZ, 2002, p. 199)

Em síntese, entendemos que ao ser apresentado a uma situação-problema, o indivíduo se depara com o obstáculo, busca mobilizar diversos recursos cognitivos, tais como procedimentos, atitudes e conhecimentos conceituais, utiliza de maneira inteligente o sistema de recursos apresentado e, na superação do obstáculo, desenvolve competências diversas, em âmbito social (como relacional e comunicativa) e científico nos procedimentos e compreensão de conceitos (FERNANDES e CAMPOS, 2013).

Para o professor, a construção de uma situação-problema não é simples e trivial, pois exige tempo, interesse e dedicação do professor. Meirieu (1998) destaca seis características centrais de uma situação-problema:

1. É proposto aos sujeitos a realização de uma tarefa;

2. É necessário a transposição do obstáculo para a execução da tarefa;

3. A transposição do obstáculo deve representar um estágio mais elevado no desenvolvimento cognitivo do sujeito.

4. O verdadeiro objetivo de cognição do educador deve ser o obstáculo a ser transposto;

5. Um sistema de restrições deve estar explícito na tarefa para que os sujeitos não executem o projeto sem enfrentar os obstáculos.

6. Para que os sujeitos vençam os obstáculos deve lhes ser fornecido os recursos para este fim (materiais e instruções).

Para auxiliar o professor na elaboração de uma situação-problema, Meirieu (1998) apresenta uma caixa de ferramentas contendo questões norteadoras utilizadas a priori:

1. Qual o meu objetivo? O que quero fazer com que o aluno adquira e que para ele representa um patamar de progresso importante? 2. Que tarefa posso propor que requeira, para ser realizada o acesso a este objetivo (comunicação, reconstituição, enigma, ajuste, resolução etc.)? 3. Que dispositivo devo instalar para que a atividade mental permita, na realização de tarefa, o acesso ao objetivo? Que materiais, documentos, instrumentos devo reunir? Que instruções-alvo devo dar para que os alunos tratem os materiais para cumprir a tarefa? Que exigências devem ser introduzidas para impedir que os sujeitos evitem a aprendizagem? 4. Que atividades posso propor que permitam negociar o dispositivo segundo diversas estratégias? Como variar os instrumentos, procedimentos, níveis de orientação, modalidades de reagrupamento? (MEIRIEU, 1998, p. 181). 
Parece consenso a necessidade de o professor "embarcar" no nível de conhecimento, ritmo de construção do conhecimento e modo de pensar e compreender de seus alunos (como formulam hipóteses, como desenvolvem competências e habilidades). Portanto, é essencial que a situação-problema seja adequada para o nível de ensino e objetivos de aprendizagem. Macedo (2002) propõe uma forma a posteriori de validação de situações-problema:

O enunciado cria um contexto ou circunstância que confere ao item uma autonomia, no sentido de ser um bom recorte ou situação-problema? A tarefa a ser realizada está bem caracterizada? É possível realizar a tarefa nos limites espaciais e temporais aceitos ou determinados na prova? As alternativas estão bem formuladas e criam obstáculos que convidam à reflexão do aluno e expressam diferentes graus de articulação entre o enunciado e a alternativa que melhor define a resolução do problema proposto? (MACEDO, 2002, p.46)

Ainda, existe a necessidade de um processo de avaliação completo e que permita aprendizagens. Meirieu (1998) defende uma avaliação ampla e múltipla, sugerindo um processo composto por três frentes que se complementam, a saber:

A) Avaliação Diagnóstica: O professor precisa conhecer o aluno, fazendo uma análise dos conhecimentos prévios, facilitando o desenvolvimento cognitivo do aprendiz.

B) Avaliação Formativa: Durante a resolução da situação-problema, o professor observa todo o processo dos alunos na busca pela resolução do problema, intervindo quando julgar necessário

C) Avaliação Somativa: Realizada ao final do processo, solicitada ao aluno, em forma de relatório, ou outro instrumento avaliativo clássico, como provas, chamadas orais e fichas de recapitulação.

Para Thurler (2002) e Santos, Almeida e Campos (2005) observar as colaborações e interações entre pesquisadores (nas áreas de ensino e pesquisa teórica ou experimental), formadores de professores nas licenciaturas e professores da educação básica, durante processos de formação continuada que valorizem a profissionalização docente, favorecem a pesquisa-ação, a prática reflexiva e interativa, como também é um estimulo a articulação e troca de informações e competências profissionais.

Diante do exposto, acreditamos que se faz necessária uma formação complementar ao professor para que ele elabore e utilize situações-problema como estratégia didática para o ensino de ciências. Neste trabalho, buscamos analisar as concepções de uma professora de ciências do nível fundamental sobre o trabalho com situações-problema, a partir de uma proposta de processo formativo, elaborada considerando a construção, a aplicação e a avaliação de situações-problema no ensino de ciências. Para isso, visamos responder ao seguinte problema de pesquisa: Qual o entendimento de uma professora de ciências do ensino fundamental sobre o trabalho com situações-problema, após um processo formativo associado a construção, aplicação e avaliação de estratégias didáticas baseadas na resolução de situações-problema? 


\section{Metodologia}

A presente pesquisa foi realizada com uma professora de ciências (doravante chamada de PI - professora investigada), que possui formação inicial em licenciatura em química, com dois anos de experiência em ensino no momento da realização da pesquisa e que integrava a rede pública estadual de Pernambuco, sob regime de contrato celetista, com atuação nos níveis fundamental e Médio em uma escola localizada no munícipio de Calumbi, sertão do Pajeú pernambucano, distante $360 \mathrm{~km}$ do Recife, capital estadual. PI ministrava aulas no Ensino Fundamental (ciências) e no Ensino Médio (lecionando as disciplinas física, química e educação física). A opção por trabalhar com um único sujeito é justificada por PI ser a única professora de ciências do município com formação na área específica.

O caminho metodológico utilizado foi composto por quatro etapas de intervenção, a saber: levantamento das concepções prévias atribuídos por $\mathrm{Pl}$ ao termo situaçãoproblema, experiência formativa, elaboração de uma situação-problema por PI e levantamento das concepções atribuídas a posteriori por PI ao termo situação-problema. Destacamos cada uma das etapas a seguir.

\section{Levantamento das concepções prévias atribuídos por $\mathrm{PI}$ ao termo situação-problema}

Procuramos PI na escola, explicamos os objetivos da pesquisa e entregamos um questionário, com cinco perguntas relacionadas com estratégias didáticas baseadas na resolução de situações-problema. As perguntas estão apresentadas no quadro 1 :

Quadro 1: Perguntas do Questionário.

1. Para você, o que são situações-problema?

2. Você já utilizou situações-problema como atividade em suas aulas de ciências?

3. Você já buscou fontes na literatura sobre situações-problema? Se sim, quais as fontes pesquisadas?

4. Você acredita que o trabalho com situações-problema pode levar a aprendizagem de conceitos científicos? Justifique.

5. De que forma pode ser avaliada a aprendizagem quando utilizamos situaçõesproblema?

As respostas foram analisadas diante do referencial teórico sobre situaçõesproblema apresentado na introdução deste artigo, com ênfase nas ideias de Meirieu (1998).

\section{Experiência formativa}

Esse momento da pesquisa teve como objetivo proporcionar uma suplementação baseada em processo formativo para que PI possa trabalhar com situações-problema como estratégia didática nas suas aulas de ciências. Sabemos que o tempo da experiência formativa não pode proporcionar uma ampla formação sobre a temática, mas 
tem potencial de proporcionar uma instrumentação inicial, suficiente para atingir os objetivos desse trabalho.

O processo de formação continuada consistiu em quatro encontros de cerca de uma hora, nos quais foram realizadas as seguintes atividades:

i) Apresentação dos objetivos da formação continuada;

ii) Apresentação de diferentes formas de definir o termo situação-problema, com base em Meirieu (1998), Macedo (2002), Câmara dos Santos (2002), Silva e Núñez (2002) e Núñez e colaboradores (2004);

iii) Discussão das orientações de Meirieu (1998) para elaboração de situações-problema.

iv) Apresentação e discussão acerca das três dimensões de avaliação propostas por Meirieu (1998) para o trabalho com estratégias didáticas centradas na resolução de situações-problema.

v) Exemplos de situações-problemas encontradas na literatura e discussão sobre seus dispositivos principais: contexto, obstáculo, sistema de restrições e sistema de recursos.

Para esta formação continuada, elaboramos um material textual de apoio, abordando as definições, como elaborar, como utilizar e como avaliar atividades centradas na resolução de situações-problema.

\section{Elaboração de uma Situação-Problema por PI}

Nesta etapa, PI elaborou uma situação-problema visando aplicação com estudantes do nono ano, última série do Ensino Fundamental, seguindo as orientações de Meirieu (1998). Pedimos ao docente que elaborasse um enunciado de uma situaçãoproblema, baseado nas orientações encontradas no material textual de apoio entregue durante a experiência formativa e as reflexões realizadas no processo, considerando todos os dispositivos a serem instalados.

Levantamento das concepções atribuídas a posteriori por PI ao termo situação-problema

Para esta etapa, realizamos uma entrevista semiestruturada com PI, para verificar o sentido atribuído por ela ao termo situação-problema depois da formação continuada proposta. Tal entrevista foi realizada em um encontro na escola, com duração de 50 minutos, organizado em três etapas diretivas, apresentadas no quadro 2:

Quadro 2: Momentos diretivos da entrevista semiestruturada

\begin{tabular}{|l|l|c|}
\hline \multicolumn{2}{|c|}{ Momento Diretivo } & \multicolumn{2}{c|}{ Pergunta da Entrevista } \\
\hline $\begin{array}{l}\text { Apresentação do } \\
\text { questionário } \\
\text { respondido para ricial } \\
\text { analisado por PI (duração de }\end{array}$ & $\begin{array}{l}\text { 1. O sentido atribuído por você ao termo situação- } \\
\text { problema mudou depois da formação continuada? Se } \\
\text { sim, explique. } \\
\text { minutos). }\end{array}$ & $\begin{array}{l}\text { Você afirmou já ter utilizado situações-problema em } \\
\text { sua prática docente. Considera como uma situação- } \\
\text { problema o que foi utilizado nestas experiências }\end{array}$ \\
\hline
\end{tabular}




\begin{tabular}{|c|c|}
\hline & anteriores? \\
\hline $\begin{array}{l}\text { Retomada da Situação- } \\
\text { problema elaborada. }\end{array}$ & $\begin{array}{l}\text { 3. Como foi o momento de elaboração da situação- } \\
\text { problema? Você teve dificuldades? } \\
\text { 4. Baseado nos pontos recursivos propostos por Macedo } \\
\text { (2002) e presentes no material textual de apoio, você } \\
\text { considera sua situação-problema adequada? }\end{array}$ \\
\hline $\begin{array}{l}\text { Retomada ao momento de } \\
\text { aplicação da estratégia } \\
\text { didática baseada na } \\
\text { resolução da situação- } \\
\text { problema, na turma do } 9^{\circ} \\
\text { ano. }\end{array}$ & $\begin{array}{l}\text { 5. Como você avalia o momento de aplicação da } \\
\text { estratégia didática baseada na resolução da situação- } \\
\text { problema? } \\
\text { 6. Você pretende continuar utilizando estratégias } \\
\text { didáticas baseadas na resolução de situações- } \\
\text { problema nas suas aulas futuras? De que forma? }\end{array}$ \\
\hline
\end{tabular}

Assim como realizamos na análise dos dados obtidos no questionário para levantamento de concepções prévias, utilizaremos a fundamentação teórica sobre as situações-problema que consta na introdução deste artigo para a análise desse momento.

\section{Resultados e Discussão}

Apresentaremos os resultados divididos em três partes: análise do levantamento de concepções prévias atribuídos por PI ao termo situação-problema, análise da situaçãoproblema elaborada por PI e análise do levantamento dos sentidos atribuídos a posteriori por PI ao termo situação-problema.

Análise do levantamento das concepções prévias atribuídos por Pl ao termo situaçãoproblema

Para PI, trabalhar com situações-problema "... trata-se de trazer situações do cotidiano para sala de aula e relacioná-las com o conteúdo desejado". Desde o início percebemos o interesse de PI em trabalhar de forma contextualizada, como podemos observar no comentário feito quando questionado acerca da utilização de situaçõesproblema em sua prática docente:

"No início do conteúdo de reações químicas, eu levei uma caixa de fósforos, uma vela, um copo de plástico e uma folha de papel. Para discutir a questão da combustão, analisamos primeiro a queima da vela e depois a queima da folha de papel". (PI)

A preocupação com o contexto, no entanto, independe do reconhecimento das situações-problema. PI parece não conhecer aspectos inerentes a à estratégia, como os sistemas de restrição e recursos, bem como o obstáculo, que não foram citados.

De acordo com PI, a situação-problema, quando bem elaborada, pode levar o aluno a ser o principal responsável por sua aprendizagem. Porém, a situação-problema deve ser motivadora, despertar o interesse e a curiosidade dos alunos, para que eles se sintam instigados em realizar pesquisas. A questão motivacional é requisito apontado por 
Meirieu (1998), que defende que as situações-problema, para cumprirem seus objetivos na construção de novos conhecimentos, devem representar três funções: erótica (relativa ao desejo e motivação em aprender, como reconhece PI), didática (associada a intencionalidade de ensino e aprendizagem) e emancipadora (que permite que os conhecimentos aprendidos possam ser utilizados em outros contextos).

“... motiva o aluno a conhecer mais sobre o tema, ela (situação-problema) deve ser bem explorada, e não apenas um início de aula. Se conseguir despertar a curiosidade dos alunos, cada professor terá um grande aliado para levar os alunos a pesquisarem, descobrirem a ser agentes de sua aprendizagem". (PI)

Com relação a avaliação, PI comenta:

"Através da participação, o interesse demonstrado pelo aluno em descobrir as respostas das perguntas levantadas pela turma ao analisar e explorar a situação-problema e ao final analisar a resposta que ele formula para os questionamentos [...]". (PI)

No geral, percebemos que PI tem uma boa noção da importância da contextualização no ensino de ciências, bem como da necessidade de formas avaliativas mais amplas, mas não demonstra conhecer aspectos importantes das situaçõesproblema. Um dos elementos principais dessa abordagem, o obstáculo a ser superado para a aprendizagem, não aparece nas respostas de PI.

\section{Análise da situação-problema elaborada por PI}

Após o processo de formação continuada, PI sugeriu uma situação-problema que abordasse o efeito estufa, utilizando a caixa de ferramentas de Meirieu (1998). As perguntas norteadoras e respostas de PI estão apresentada no quadro 3 :

Quadro 3: Perguntas norteadoras $\mathrm{x}$ respostas de PI

\begin{tabular}{|c|c|}
\hline Perguntas Norteadoras & Respostas de PI \\
\hline $\begin{array}{l}\text { 1. Qual meu objetivo com esta } \\
\text { questão? O que eu quero que o } \\
\text { aluno adquira e que represente } \\
\text { um patamar de progresso } \\
\text { importante para ele? }\end{array}$ & $\begin{array}{l}\text { O principal objetivo na elaboração da situação- } \\
\text { problema foi o de desenvolver nos alunos a } \\
\text { capacidade de pensar criticamente mediante uma } \\
\text { situação de conflito - eles descobrirão que seus } \\
\text { conhecimentos prévios não são suficientes para } \\
\text { resolver o problema sugerido. }\end{array}$ \\
\hline $\begin{array}{l}\text { 2. Quais tarefas devo propor para } \\
\text { que os alunos consigam chegar ao } \\
\text { patamar de progresso desejado? }\end{array}$ & $\begin{array}{l}\text { Os alunos teriam que explicar os motivos da maior } \\
\text { temperatura no interior de um carro fechado e } \\
\text { estacionado ao sol em relação a temperatura } \\
\text { ambiente, externa ao carro, passado algum tempo. }\end{array}$ \\
\hline $\begin{array}{l}\text { 3. Que dispositivo devo instalar } \\
\text { para que a atividade mental } \\
\text { permita, na realização da tarefa, o } \\
\text { acesso ao objetivo? }\end{array}$ & \\
\hline $\begin{array}{l}\text { Que materiais, documento } \\
\text { instrumentos devo reunir? }\end{array}$ & $\begin{array}{l}\text { PI informa que vai trabalhar com o artigo "A } \\
\text { Química no Efeito Estufa" (TOLENTINO e ROCHA- }\end{array}$ \\
\hline
\end{tabular}




\begin{tabular}{|c|c|}
\hline $\begin{array}{l}\text { Que instruções-alvo devo dar para } \\
\text { que os alunos tratem os materiais } \\
\text { para cumprir a tarefa? }\end{array}$ & $\begin{array}{l}\text { FILHO, 1998). } \\
\text { O trabalho em grupo e a liberdade de interação } \\
\text { com o professor durante a resolução da situação- } \\
\text { problema para garantir a superação do obstáculo. }\end{array}$ \\
\hline $\begin{array}{l}\text { Que exigências devem ser } \\
\text { introduzidas para impedir que os } \\
\text { sujeitos evitem a aprendizagem? }\end{array}$ & $\begin{array}{l}\text { Os alunos devem ser encorajados a superar o } \\
\text { obstáculo do problema, utilizando o sistema } \\
\text { recursos para atingir a aprendizagem, e o sistema } \\
\text { de restrição para que não utilizem atalhos para } \\
\text { evitar a construção do conhecimento. Ressalto que } \\
\text { nenhum aluno pode ser forçado a responder a } \\
\text { situação-problema. }\end{array}$ \\
\hline $\begin{array}{l}\text { 4. Que atividades posso propor que } \\
\text { permitam negociar o dispositivo } \\
\text { segundo diversas estratégias? } \\
\text { Como variar os instrumentos, } \\
\text { procedimentos, níveis de } \\
\text { orientação, modalidades de } \\
\text { reagrupamento? }\end{array}$ & $\begin{array}{l}\text { Visando a resolução da situação-problema, } \\
\text { realizarei uma leitura coletiva do texto, comentando } \\
\text { e debatendo os principais pontos com os alunos. }\end{array}$ \\
\hline
\end{tabular}

Após correções para melhorar a coesão e coerência do texto, a versão final foi:

Um maior bloqueio da radiação infravermelha é observado com 0 aumento do teor atmosférico dos chamados gases-estufa e, consequentemente, pode causar um aumento do efeito estufa: aquecimento da atmosfera e aumento da temperatura da superfície terrestre. De acordo com o texto auxiliar e seus conhecimentos sobre o tema, explique por que a temperatura interna de um carro fechado e exposto ao sol é maior que a temperatura ambiente.

Podemos identificar claramente os elementos fundamentais de uma situaçãoproblema na perspectiva trabalhada: contexto (efeito estufa), sistema de recursos (texto auxiliar fornecido por $\mathrm{PI}$ ), sistema de restrições ("de acordo com o texto auxiliar e seus conhecimentos sobre o tema") e obstáculo (conhecimentos sobre gases, efeito estufa, temperatura e meio ambiente).

Análise do levantamento de concepções atribuídas a posteriori por PI ao termo situaçãoproblema

A seguir apresentaremos as respostas dadas por PI para cada uma das seis questões da entrevista semiestruturada. As perguntas 1 e 2 correspondem ao primeiro momento diretivo, no qual, por 15 minutos, apresentamos as respostas fornecidas no questionário para levantamento de sentidos prévios.

Pergunta 1: O sentido atribuído por você ao termo situação-problema mudou depois da formação continuada? Se sim, explique. 
"Eu não digo mudou, eu digo ampliou ou aumentou mais um pouquinho... assim... eu entendia situação-problema como situação-problema, menos depois do que você apareceu. Assim... depois do estudo e do treinamento que foi feito, então assim... estruturou... tipo os objetivos, cada etapa, cada passo os conceitos ficaram mais claros". (PI)

Ao não identificar na resposta uma definição sobre situações-problema, insistimos e perguntamos: O que você entende por uma situação-problema? Qual a sua definição dê situação-problema? Desta vez, PI respondeu:

"Situação-problema é você colocar diante do aluno uma... como é que eu posso dizer... uma situação do dia-a-dia dele, uma situação que seja, que possa transpor para o conteúdo e através dessa situação ele possa perceber que nem tudo que ele imagina e sabe sobre a situação é o suficiente pra poder responder as outras coisas em relação ao mundo químico, ao mundo das ciências, ao mundo cientifico e que ele precisa de alguns conhecimentos a mais..." (PI)

Notamos uma considerável mudança no que PI entende por situação-problema. A sua resposta se enquadra nos pressupostos teóricos considerados para essa pesquisa. Percebemos que PI considera que as situações-problema apresentam recortes da vida real, presentes no cotidiano dos estudantes, reconhece a presença do obstáculo ("nem tudo que ele imagina e sabe sobre a situação é o suficiente para poder responder...") e a importância de um sistema de restrição e recursos que possibilite a aprendizagem e superação deste obstáculo. De acordo com Meirieu (1998), são essas as características centrais das situações-problema, e a presenta dos dispositivos de restrição e recursos permite que o obstáculo possa ser superado e, consequentemente, a estratégia didática seja exitosa em relação aos objetivos de aprendizagem.

\section{Pergunta 2: Você afirmou já ter utilizado situações-problema em sua prática docente. Considera como uma situação-problema o que foi utilizado nestas experiências anteriores?}

"Sim, pois a vela é algo que eles usam em casa. E depois que queimou foi levada para casa. Já faltou energia na sua casa? O que vocês procuram? Qual é a primeira procura de vocês? Aí eles disseram a vela. E como é a reação da vela? O que a vela faz? Ah, ela ilumina. Mas qual é a reação da vela? Então eles começaram a perceber que realmente era uma situação-problema e que $o$ pensamento deles, o que eles pensam sobre a vela não era o suficiente para entender o que estava acontecendo com a vela para ela iluminar. Daí a gente começou a trabalhar as coisas do livro mesmo, as coisas da revista sobre a combustão, começamos desenvolvendo até que eles agora sabem tudo o que acontece com a vela". (PI)

Podemos perceber que PI utiliza como contexto da problematização objetos e situações cotidianas dos estudantes. No entanto, a estratégia evidenciada parece com o uso do contexto da queima de uma vela para entender o processo de combustão, sem caracterizar uma situação-problema. Podemos inferir nesse momento da análise que, embora tenha reconhecido os elementos centrais que caracterizam uma situação- 
problema, PI exemplifica a utilização anterior da estratégia a partir de um caso em que o foi feito o uso da química do cotidiano, mas sem de fato constitui uma situação-problema, de acordo com o referencial teórico associado a pesquisa: Meirieu (1998), Silva e Núñez (2002) e Macedo (2002).

As perguntas 3 e 4 estão relacionadas à elaboração da situação-problema.

\section{Pergunta 3: Como foi o momento de elaboração da situação-problema? Você teve dificuldades?}

PI deixa evidente em sua resposta que a maior dificuldade encontrada é contextualizar o conhecimento científico para o conhecimento cotidiano dos alunos.

"Eu achei... não é que eu achei difícil e nem fácil, e nem assim como é que se diz... é... também o assunto que foi colocado, que é o efeito estufa, ele é um assunto do cotidiano e ao mesmo tempo complexo, então assim... para falar na linguagem deles e colocar para o dia deles eu achei um pouquinho mais complicado, mas no momento eu consigo fazer outra com mais facilidade. " (PI)

De acordo com Santos (2005) a maior dificuldade encontrada pelos professores na elaboração de situações-problema é a contextualização. Esta autora aponta as possíveis causas para este fato: a falta de costume dos professores de química em procurar enxergar a química por trás da vida. Segundo a mesma autora, os professores de química deveriam sempre se questionar sobre a química que os cerca, ou seja, buscar contextos que estejam relacionados a atividades cotidianas dos estudantes.

Pergunta 4: Baseado nos pontos recursivos propostos por Macedo (2002) e presentes no material textual de apoio, você considera sua situação-problema adequada?

"Mas foi baseado nele mesmo, não só no outro [PI faz referência a Meirieu), à medida que estava construindo, estava olhando para os pontos levantados pelos dois... que eles colocavam e fui seguindo o que eles realmente estavam dizendo. Então, sim, correlacionando com os pontos de Macedo, eu considero válida. " (PI)

No início da resposta, percebemos que PI encarou a pergunta como um inquérito, no sentido de verificar se realmente os pontos levantados pelos autores foram considerados. Porém, podemos inferir na pergunta, embora possivelmente mal compreendida, que as caixas de ferramenta a priori e a posteriori foram consideradas para elaboração da situação-problema.

Por fim, o terceiro momento diretivo foi composto por duas perguntas (5 e 6), baseadas na aplicação da situação-problema criada em contexto de sala de aula. Tal aplicação ocorreu em apenas uma aula, sem nenhuma preparação prévia. Embora tenha sido apontado na experiência formativa a necessidade da elaboração de uma intervenção didática, para que o sistema de recurso seja bem apresentado, para reconhecimento do obstáculo e para que a situação tenha sido assimilada (MEIRIEU, 1998; SIMÕES NETO, MARCELINO-JR. e CAMPOS, 2013), foi desta forma que PI organizou seu trabalho.

Pergunta 5: Como você avalia o momento de aplicação da estratégia didática baseada na resolução da situação-problema? 
"Eu digo que da teoria pra prática é realmente diferente, principalmente... é em uma escola em que os alunos... eles não se preocupam com seu cotidiano de forma ampla... eles se preocupam em viver o momento, e o momento deles é a festa, é a novela, é a música... são essas coisas, e não... realmente o mundo. Então, quando a gente coloca eles pra pensar no mundo, o que está acontecendo com o mundo, qual o futuro deles e o que eles podem fazer pra ajudar, então... isso aí faz com que eles fiquem um pouquinho 'desorientados'. $\mathrm{Na}$ hora da aplicação eu senti que eles ficaram 'tontos', disseram eu sei, eles sabiam a resposta, mas não sabiam explicar. Eles sabiam o que estava acontecendo na situação do carro, mas eles não conseguiam expor de forma clara, assim... de forma científica... o que estava acontecendo. E quando a gente começava a puxar e, começava a sair tudo, meio atrapalhado, mas... quando eles falavam mesmo atrapalhado dava pra perceber que eles sabiam o que estavam falando".

Percebemos no discurso de $\mathrm{PI}$ a pouca motivação em responder a situaçãoproblema. A preocupação não reside na aprendizagem, mas apenas em obter boas notas. Ou seja, a motivação é extrínseca (POZO e GOMEZ CRESPO, 2009) e aparentemente é muito difícil se atingir a função erótica das situações-problema. Assim, segundo o relato de $\mathrm{Pl}$, podemos inferir que a busca é pela realização da tarefa de qualquer forma, para se ver livre, e não para aprender (MEIRIEU, 1998).

\section{Pergunta 6: Você pretende continuar utilizando estratégias didáticas baseadas na resolução de situações-problema nas suas aulas futuras? De que forma?}

"Eu não consigo ensinar sem usar situação-problema [...] até coloquei no questionário também... pelo fato da química... ser distante do aluno, já ser considerada a matéria 'monstro', e quem estuda fica doido, é louco... Então, se você chegar pra eles e pedir pra eles decorarem, pra eles falarem, por exemplo, do efeito estufa, só chegar na sala e explicar o gás carbônico e os CFCs, o metano... quimicamente e como acontece quimicamente, sem aquela coisa... que acontece com ele dentro do carro, acontece com ele dentro de casa, acontece com ele quando, no verão... os invernos estão menos frios. Então, explicando a eles a situação que estão passando, acho que teria um maior interesse pra eles e... se não aplicar situação-problema não haverá interesse para o aluno... existe o interesse de passar e ganhar nota então ele vai decorar... e se ele decora ele não aprende". (PI)

PI retoma a ideia da motivação extrínseca, e aponta que a utilização de situaçãoproblema pode auxiliar a desmitificar a ciência, a superar a imagem distorcida (especificamente da química), presente nos modos de pensar dos alunos. Tais distorções, segundo Cachapuz e colaboradores (2011), associadas ao ensino, contribuem para o insucesso na ciência escolar.

Analisando as respostas de uma maneira geral, percebemos que PI consegue entender o que é uma situação-problema, embora na hora de resgatar trabalhos anteriores, considera uma simples relação com o cotidiano, a partir da utilização de uma vela, em associação com a explicação sobre a reação de combustão, como situaçãoproblema, embora não apresente os elementos estruturantes propostos por Meirieu 
(1998). Ainda, percebemos que o trabalho com situação-problema pode ser, segundo PI, uma estratégia didática eficiente para superação da assepsia na ciência escolar, na existência única de motivações extrínsecas e na visão de ciência em sala de aula. No entanto, destacamos que, em alguns momentos, como no início e fim da resposta a sexta questão, aparentemente PI considera o trabalho com situações-problema como a única forma de minimizar aspectos negativos no ensino e aprendizagem da química escolar.

\section{Considerações Finais}

Previamente, PI desconhecia o referencial teórico que norteia o trabalho com situações-problema. No início, ele entende que existe algo diferente e mais complexo numa situação-problema quando comparada a um exercício tradicional, contudo, percebemos que o significado do termo é pouco estruturado e que as definições recorrentes na literatura são desconhecidas, embora tenha mencionado utilização de estratégias baseada em situações-problema em suas aulas. Após a experiência formativa, sua compreensão do que significa o termo Situação-problema está mais próximo do sentido estabilizado na literatura (MEIRIEU, 1998; SILVA e NÚÑ̃EZ, 2002) que foi usada como marco teórico para essa pesquisa.

PI considerou que a prática da aplicação da situação-problema em pouco se assemelhou ao que é preconizado pela literatura. Segundo ele, os alunos não estavam preocupados em resolver a situação-problema, de forma a construírem o conhecimento. Esse fato confirma o que Meirieu (1998) levantou, que sempre inventamos para não termos que aprender e, por isso não se deve atribuir a má vontade dos alunos o fato de tentarem executar alguma tarefa sem aprender, mas sim tentar motivá-los a querer buscar a solução para aquela problemática que lhe está sendo proposta.

\section{Referências}

BEZERRA, B. H. S.; AMARAL, E. M. R. Abordagem de temas sociocientíficos em periódicos nacionais de Ensino de Ciências publicados no período de 2005-2014. Em: $X$ Encontro Nacional de Pesquisa em Educação em Ciências (ENPEC). 2015. Anais... Águas de Lindóia: Associação Brasileira de Pesquisa em Educação em Ciências (ABRAPEC), p. 1-8, 2015.

CACHAPUZ, A. F. Epistemologia e ensino das ciências no pós-mudança conceptual: análise de um percurso de pesquisa. Em: II Encontro Nacional de Pesquisa em Educação em Ciências (ENPEC), 1999, Anais... Valinhos-SP: Associação Brasileira de Pesquisa em Educação em Ciências (ABRAPEC), p. 1-10, 1999.

CACHAPUZ, A.; GIL-PEREZ, D.; CARVALHO, A.M.P.; PRAIA, J.; VILCHES, A. A Necessária Renovação no Ensino de Ciências. $2^{\mathrm{a}}$ ed. São Paulo: Cortez. 2011.

CÂMARA DOS SANTOS, M. Algumas concepções sobre o ensino-aprendizagem em Matemática. Educação Matemática em Revista, n. 1 e 2, p. 150-156, 2002.

CHASSOT, A. I. Catalisando Transformações em Educação. ljuí-RS: Editora da Unijuí. 1993. 
CHASSOT, A. I. Para quem é útil o ensino? Alternativas para um ensino (de Química) mais crítico. Canoas-RS: Ulbra. 1995.

FERNANDES, L. S.; CAMPOS, A. F. Elaboração e Aplicação de uma Intervenção Didática Utilizando Situação-Problema no Ensino de Ligação Química. Experiências em Ensino de Ciências, v. 9, n. 1, p. 37-49, 2014.

MACEDO, L. Situação-problema: forma e recurso de avaliação, desenvolvimento de competências e aprendizagem escolar. Em: PERRENOUD, P.; THURLER, M. G.; MACEDO, L.; MACHADO, N. J.; ALESSANDRINI, C. D. As competências para ensinar no século XXI: a formação dos professores e o desafio da avaliação. Porto Alegre: Artmed, 2002.

MERIEU, P. Aprender... sim, mas como? 7ª ed. Porto Alegre: Artimed. 1998.

NUÑEZ, I. B.; MARUJO, M. P.; MARUJO, L. E. L.; DIAS, M. A. S. O Uso de Situaçõesproblema no Ensino de Ciências. In: NUÑEZ, I. B.; RAMALHO, B. L. Fundamentos do Ensino-Aprendizagem das Ciências Naturais e da Matemática: O Novo Ensino Médio. Porto Alegre: Editora Sulina, 2004.

POZO, J. I.; GOMEZ CRESPO, M. A. A Aprendizagem e o Ensino de Ciências - Do Conhecimento Cotidiano para o Conhecimento Científico. 5 ed. Porto Alegre: Artmed, 2009.

SANTOS, D. M. O Desenvolvimento de Competências dos (as) Professores (as) de Química no Trabalho com Situações-Problema. 2005. 115 p.; Dissertação (Mestrado em Ensino das Ciências). Universidade Federal Rural de Pernambuco, Programa de PósGraduação em Ensino das Ciências, Recife, 2005.

SANTOS, V. T.; ALMEIDAS, M. A. V.; CAMPOS, A. F. Concepções de professores de Química do Ensino Médio sobre a Resolução de Situações-problema. Revista Brasileira de Pesquisa em Educação em Ciências, Porto Alegre, v. 5, n. 3. p. 25-37, 2005.

SILVA, S. F.; NUÑEZ, I. B. O ensino por problemas e trabalho experimental dos estudantes reflexões teórico-metodológicas. Química Nova, v. 25, n. 6B. p. 1197-1203, 2002.

SIMÕES NETO, J. E.; CAMPOS, A. F.; MARCELINO-JR., C. A. C. Abordando a Isomeria em Compostos Orgânicos e Inorgânicos: Uma Atividade Fundamentada no Uso de SituaçõesProblema na Formação Inicial de Professores de Química. Investigações em Ensino de Ciências, v. 19, n. 2, p. 327-346, 2013.

THURLER, M. G. O desenvolvimento profissional dos professores: novos paradigmas, novas práticas. Em: PERRENOUD, P.; THURLER, M. G.; MACEDO, L.; MACHADO, N. J.; ALESSANDRINI, C. D. As competências para ensinar no século XXI: a formação dos professores e o desafio da avaliação. Porto Alegre: Artmed, 2002.

TOLENTINO, M. ROCHA-FILHO, R. C. A Química no efeito estufa. Química Nova na Escola, n. 8, p. 10-14, 1998.

ZANON, L. B.; PALHARINI, E. M. A química no Ensino Fundamental de Ciências. Química Nova Na Escola, n. 2, p. 15-18, 1995.

Submissão: 05/01/2015

Aceite: 01/06/2017 